\title{
Assessment of Quality Indicators of Pressed Biofuel Produced from Coarse Herbaceous Plants and Determination of the Influence of Moisture on the Properties of Pellets
}

\author{
Algirdas Jasinskas ${ }^{1, *(\mathbb{D})}$, Vytautas Kleiza ${ }^{2} \mathbb{D}$, Dionizas Streikus ${ }^{1}$, Rolandas Domeika ${ }^{1} \mathbb{D}$, Edvardas Vaiciukevičius ${ }^{1}$, \\ Gvidas Gramauskas ${ }^{1}$ and Marvin T. Valentin ${ }^{3}$
}

Citation: Jasinskas, A.; Kleiza, V.; Streikus, D.; Domeika, R.;

Vaiciukevičius, E.; Gramauskas, G.;

Valentin, M.T. Assessment of Quality Indicators of Pressed Biofuel Produced from Coarse Herbaceous Plants and Determination of the Influence of Moisture on the Properties of Pellets. Sustainability 2022, 14, 1068. https://doi.org/ $10.3390 /$ su14031068

Academic Editor: Barry D. Solomon

Received: 14 December 2021

Accepted: 15 January 2022

Published: 18 January 2022

Publisher's Note: MDPI stays neutral with regard to jurisdictional claims in published maps and institutional affiliations.

Copyright: (C) 2022 by the authors. Licensee MDPI, Basel, Switzerland. This article is an open access article distributed under the terms and conditions of the Creative Commons Attribution (CC BY) license (https:// creativecommons.org/licenses/by/ $4.0 /)$.
1 Department of Agricultural Engineering and Safety, Faculty of Engineering, Vytautas Magnus University Agriculture Academy, Studentu Str. 15A, Akademija, LT-53362 Kaunas, Lithuania; streikusdionizas@gmail.com (D.S.); rolandas.domeika@vdu.lt (R.D.); edvardas.vaiciukevicius@vdu.lt (E.V.); g.gramauskas@gmail.com (G.G.)

2 Department of Mathematics and Statistics, Faculty of Informatics, Vytautas Magnus University, K.Donelaicio 58, LT-44248 Kaunas, Lithuania; vytautas.kleiza@vdu.lt

3 Department of Agricultural and Biosystems Engineering, College of Engineering and Applied Technology, Benguet State University, Km. 5, La Trinidad 2601, Philippines; m.valentin@bsu.edu.ph

* Correspondence: algirdas.jasinskas@vdu.lt

\begin{abstract}
Three coarse herbaceous energy plants-such as Miscanthus (Miscanthus sinensis), sida (Sida hermaphrodita Rusby) and cup plant (Silphium perfoliatum L.) —were grown and investigated in the experimental fields of Vytautas Magnus University Agriculture Academy, and the technical means of plant processing and utilization for solid biofuel were investigated. The physical-mechanical properties and quality indicators (moisture content, biometrical properties, density, and resistance to compression) of coarse stem herbaceous plants milled and compressed into $6 \mathrm{~mm}$ diameter pellets were investigated. The moisture content of the tested pellets was sufficiently low and ranged from $8.7 \%$ to $9.6 \%$. The highest density was that of sida pellets $\left(1072.3 \pm 43.4 \mathrm{~kg} \mathrm{~m}^{-3} \mathrm{DM}\right)$, and the lowest density was that of Miscanthus pellets $\left(713.5 \pm 67.1 \mathrm{~kg} \mathrm{~m}^{-3} \mathrm{DM}\right)$. In order to evaluate the influence of moisture content on the properties of biofuel pressed into pellets, the density and the destructive compressive force of the different-moisture pellets were investigated and their change in the range of $5-15 \%$ pellet moisture content was evaluated. Criterion $k$ was calculated to determine the effect of moisture on the pellet quality indicators (density, destructive compressive force, and lower heating value), and the following results were obtained: the highest influence of moisture on density was observed in sida $(k=34.280)$, on destructive compressive force in Miscanthus $(k=14.5)$, and on the lower heating value, also in Miscanthus $(k=0.198)$. After a comprehensive investigation and evaluation of these properties, an empirical model suitable for practical use was developed and prepared. Emissions of harmful gases, such as carbon monoxide, carbon dioxide, and nitrogen oxides, were determined when various coarse stem herbaceous energy plants were burned. The determined emissions of harmful gases into the environment did not exceed the permissible values.
\end{abstract}

Keywords: coarse stem plants; solid biofuel; milling; granulation; quality indicators; burning; emissions; energy evaluation

\section{Introduction}

As countries develop and pursue sustainable economic growth, there is an increasing focus on renewable energy resources. These are solar, wind, hydro, geothermal energy, and plant biomass, which is widely used in Lithuania and other countries [1,2]. Biomass is an environmentally friendly energy source, which can reduce carbon emissions, and the use of biomass can be an alternative to fossil fuels, which can reduce GHG emissions. Researchers around the world are investigating and developing biomass compaction technologies, such as granulation, briquetting, and others $[3,4]$. 
Lithuania has particularly good conditions for growing and using wood, agricultural, and energy crops for energy purposes. In the past, the main source of fuel was wood from forests, but in recent years biomass from various plants has been used for this purpose. There are many arable lands in Lithuania that could be used to grow, for example, willow, Miscanthus (so-called elephant grass), or sida, which would provide high-quality biofuel with high calorific value. Such plant biomass has low greenhouse gas emissions, helps to create additional jobs, and increases energy independence, as well as benefits rural development [1,5].

The use of alternatives to biomass cultivation opens the door to a wide range of applications. From an economic point of view, local food is much more useful than imported food, but many do not even think before choosing one product or another. Pellets made from energy crops have long been able to provide strong support to local farms, especially in regions where land is less fertile for growing cereal crops [5,6]. Such plant biomass is completely unaffected by soil and weather conditions, and it does not depend on the use of fertilizers. It is not afflicted by disease, is long-lasting, and could easily compete with wood fuel. It is safe to say that this would be a very attractive alternative for Lithuania looking for new innovative solutions.

The use of renewable energy resources, and biomass in particular, is a major global concern. Environmentally friendly fuels would help solve the energy problems associated with greenhouse gas emissions. Research on the most optimal energy crops has long been carried out in Lithuania and other European Union countries [5,6]. Considering the agreements between the countries and the common strategy, Lithuania has submitted its commitments to the European Union that 23\% of Lithuania's total energy balance will consist of biomass by 2020, and this agreement has been fully implemented. Biomass currently accounts for about $90 \%$ of all renewable energy in Lithuania [7].

Environmental preservation is of great importance in protecting and nurturing the nature of our country, which is why we all need to take part in preserving the natural environment and securing its future. Sustainability and ecology are key aspects of environmental preservation. Sustainable and environmentally friendly products can be a great source of renewable energy. Energy plantations could be a great example of sustainable and environmentally friendly industrial production. Chips obtained from the shredding of plant biomass would be used in energy companies and pellets in households [8].

Miscanthus (Miscanthus sinensis) is a perennial herbaceous plant of the genus Poaceae that grows with glossy, hanging leaves. It can grow up to 2.5-3 m, sometimes up to $4 \mathrm{~m}$ height, and is also known as Chinese reed. It loves heat and humidity but is not sufficiently resistant to dry weather and cold [9].

This tall and long-living plant has a number of advantages: it has a high potential to absorb and convert solar energy, resulting in a high yield of plant biomass during the photosynthesis process. These plants can be widely used in a variety of fields, one of which is energy. Because of its high content of lignin, Miscanthus biomass can be used to produce cellulose, and it is also environmentally friendly due to its low emissions of nitrogen oxides [10].

When planning the cultivation of elephant grass, it is necessary to choose an area of land that ensures minimum costs for mechanized tillage, crop care, and harvesting [11]. The biomass of Miscanthus is high in calories, as these plants store $17 \mathrm{MJ}$ of energy per $1 \mathrm{~kg}$ of dry mass. For example, the energy value of $20 \mathrm{t}$ of plant biomass is equivalent to 8 tonnes of coal. These plants also accumulate small amounts of minerals because they are stored in the rhizomes during colder weather [5]. Miscanthus does not require large amounts of fertilizer, which does not lead to any significant increase in biomass yield [12].

The ash from the combustion of Miscanthus accounts for about $4-5 \%$ of the total mass, has good chemical, physical, and mineral properties, and can be used as an eco-efficient additive in cement production and as a fertilizer for plants [6,13]. Miscanthus can also be used to make wood fiber, and some species are suitable for rapid pyrolysis to obtain bio-oils [14,15]. 
Sida (Sida hermaphrodita) is another big stem herbaceous plant that can be grown and used for energy purposes. Sakhalin, Japanese, and hybrid species of sida are widely grown and used. Sida grows well in areas with rainfall of 500-600 mm, can reach a height of 3-4 m, and reproduces by seed. However, it would also be possible to propagate it with roots (like Miscanthus). The yield of sida biomass can reach up to $20 \mathrm{tha}^{-1}$ of DM (dry mass) [16].

The results of various scientific studies show that the net calorific value of sida is as high as $18 \mathrm{MJ} \mathrm{kg}^{-1}$, which is slightly different from the net calorific value of pine and spruce (19.3-19.5 $\mathrm{MJ} \mathrm{kg}^{-1}$ ) [17]. However, in terms of the growth rate of sida, it can yield twice as much energy per hectare per year as wood. Another major advantage for farmers is that the same techniques can be used when harvesting and processing other tall crops, such as maize, Jerusalem artichokes, and others [12].

In intensively farmed regions, the growing of sida can help us solve ecological problems, such as reducing soil erosion and nitrate leaching, as well as increasing biodiversity and economic profitability for the farmer. The interest in this plant species, which began in Poland 18-20 years ago, has been steadily growing, and various uses of these plants have been explored by Polish and German researchers [18]. The extract of Sida hermaphrodita has an effective antifungal effect against the clinical strain of Candida albicans and is moderately strong against other Candida strains studied [19].

Cup plant (Silphium perfoliatum L.) is a species of flowering plant of the family Asteraceae, native to eastern and central North America. In summer, it is an upright herbaceous perennial with triangular toothed leaves and sun-like yellow composite flower petals. It is a plant belonging to the genus Silphium of the astral family. Based on the data from a four-year study, annual growth conditions and nitrogen fertilizers were the main factors influencing the increase of its dry mass (DM) [20].

It is important to study not only the peculiarities of growing these tall perennial grasses but also the technical means of preparing plant biomass for biofuel, to evaluate the quality indicators of shredding and milling these plants, and to determine the main physical-mechanical properties and calorific value. The biomass of these plants is ready for use in the production of biofuel [1]. Biomass can be used to produce high calorific synthetic gas, a promising advanced fuel that can be produced by thermochemical gasification [21]. According to Romanian researchers, the potential for bioremediation of vegetation leaves of plants of Silphium perfoliatum L. growing in heavy metal-contaminated soil is quite high [22]. Lithuanian researchers also studied cup plants and found that in many cases growth conditions and nitrogen fertilization were two decisive factors for all studied parameters: number of stems per plant, stem height, green and dry masses, and yield [23]. In many countries, perennial energy crops and large-stem plants are the most promising raw materials for energy production [16]. Wood, wood waste, straw, and various species of energy plants account for a larger share of thermal energy production in the total energy balance. New combustion technologies allow the efficient use of renewable fuels in bioelectric power plants and households.

The increasing use and uptake of more renewable energy resources for energy purposes requires not only the development of new technologies but also wider research into the properties of herbaceous plants. Thus, after a thorough study of the physicalmechanical and thermal properties of the raw material and the selection of appropriate equipment for processing and combustion, high-quality and convenient fuels may be placed on the market for consumers [5,8].

For a better understanding of plant biomass suitability for biofuel production, it is very important to know the elemental and chemical composition of biomass, which is defined as the percentage of chemical elements that make up biomass [24,25]. Carbon, hydrogen, and oxygen are the most essential chemical components of solid fuels, during the combustion of which carbon and oxygen interact in an exothermic reaction to form $\mathrm{CO}_{2}$ and $\mathrm{H}_{2} \mathrm{O}$ [26]. The quality of biofuel is also affected by other important factors, such as the physical-mechanical properties of the material, the preparation and moisture content of the raw material, and others. 
After analyzing the sources of information, the aim of the presented work was formulated: to evaluate the possibilities of growing and using coarse herbaceous plants (Miscanthus, sida, and cup plants) for energy conversion, to determine and comprehensively evaluate the physical-mechanical and energy properties of plant granules and their effect on moisture, and to evaluate the impact on the environment when burning the produced pellets.

New and valuable research is planned not only from a scientific but also from a practical point of view, as the production process of granulated biofuel will be analyzed and the factors influencing the quality of coarse herbaceous plant pellets will be identified. In addition, the modeling of plant pellets will be performed according to the studied and selected indicators influencing their properties.

\section{Materials and Methods}

\subsection{Production of Pressed Biofuel and Investigation of Properties of the Produced Pellets}

The technology and equipment for the production of biofuel pellets depend on the quality of the raw material, moisture, and its fractional composition. Large-scale herbaceous plants, such as Miscanthus, sida, and cup plant, grown in the test fields of the Lithuanian Research Centre for Agriculture and Forestry, Institute of Agriculture, and Vezaiciai branch were used in this research. After harvesting and preparing these plants for granulation, tests are carried out to determine whether their moisture content exceeds $20 \%$. If so, they are first dried, then crushed, and ground into a coarse powder.

The production of pellets consists of the following stages [27], so pellet production studies were performed based on the following recommendations:

- Drying of raw materials. Before producing the pellets, the moisture content of the raw material was reduced to the required level (13-15\%);

- $\quad$ Biomass shredding. The raw material used to make pellets can vary greatly in particle size, so the investigated plants were chopped and milled into 1-2 $\mathrm{mm}$ particles, then the raw material was homogenized and mixed well before pressing;

- Pellet pressing. The granules were produced with special granulation equipment;

- Pellet cooling. Freshly made pellets are hot, so to prevent them from igniting spontaneously, the produced pellets were cooled in a special tank.

The granulation technology and equipment used depend on the raw material, its fractional composition, and moisture. The research was performed in Lithuania, in Vytautas Magnus University Agriculture Academy laboratories. A drum shredder of the forage harvester Maral 125 (Fortschritt, East Germany) was used to shred the plant stems to $15-20 \mathrm{~mm}$ particles. The produced chopped material must be milled into flour (1-2 $\mathrm{mm}$ particles). Thus, a mill Retsch SM 200 (Retsch, Berlin, Germany) was used for flour production, using a sieve with round holes $2 \mathrm{~mm}$ in diameter.

The milling quality and the fractional composition of the flour were determined by sieving a $0.5 \mathrm{~kg}$ sample using a Haver EML Digital plus sieve shaker (Haver \& Boecker, Oelde, Germany) with a set of $200 \mathrm{~mm}$ diameter sieves with the following mesh sizes: 0, 0.5, 1 , and $2 \mathrm{~mm}$ in diameter. The weight remaining on the sieve is calculated as a percentage of each fraction. Each test is performed five times.

A low-power granulator (up to $200-300 \mathrm{~kg} \mathrm{~h}^{-1}$ ) with a horizontal matrix Peleciarka (Polemix, Zhmerinka, Poland) was used for flour pressing. The diameter of the produced granules was $6.0 \pm 0.3 \mathrm{~mm}$. Laboratory equipment of Vytautas Magnus University was used to determine the biometrical, physical, and mechanical properties of coarse stem herbaceous plant pellets. These tests were performed to determine the density and strength of the pellets, as these properties are important during the period of pellet handling, transportation, and delivery to the burning implements of a boiler.

The biometrical properties and density of the granules are determined by measuring, weighing, and calculating their volume and density. The strength of the granules was determined by measuring the destructive compressive force using an Instron 5960 (Instron Universal Tester, Norwood, MA, USA). For the test, a single cylindrical granule was placed 
on a horizontal plate and a vertical force of $8.0 \mathrm{~mm}$ in diameter pressure rod was applied vertically. The speed of movement of the pressure rod was $1 \mathrm{~mm} \mathrm{~min}^{-1}$, and it was stopped after breaking the pellet. The measurement data were recorded on a computer using a special program.

The moisture content of the pellets was determined in a chemical laboratory according to the methodology provided in the standard EN ISO 18134-1: 2015 [28]. To determine moisture, five samples were taken at random with a chaff of chopped plants, weighed, and dried until the mass of the sample remained constant at $105^{\circ} \mathrm{C}$. The dried samples were weighed again, then the empty dishes were weighed, and the moisture content of each sample was calculated. The density of the granules was determined by measuring and weighing the granules and calculating their volume and density.

The analysis of the elemental composition, ash content, and calorific value of the produced biofuel pellets was performed in the Laboratory of Thermal Equipment Research and Testing of the Lithuanian Energy Institute (LEI) according to the standard methodology valid in Lithuania and European countries.

When assessing the elemental composition of the pellets, the amounts of carbon, hydrogen, nitrogen, and sulfur were determined in accordance with the requirements of the standard LST EN ISO 16948: 2015 [29]. Oxygen content was determined by difference: $\mathrm{O} \rightarrow 100 \%-A s h \%-C \%-H \%-N \%-S \%$. Ash tests were performed in accordance with the requirements of the standard LST EN ISO 18122: 2016 [30]. Calorific value tests were performed in accordance with the requirements of LST EN ISO 18125: 2017 standard [31].

The elemental composition of the granules: the total carbon, hydrogen, nitrogen, sulfur, and oxygen content was determined using a Flash 2000 element analyzer (measurement error $0.001-0.3 \%$ ). Ten pellets (approximately $100 \mathrm{~g}$ ) were used for each study, and each experiment was repeated three times.

The ash content of biofuel pellets determines the amount of ash remaining after the pellets are burned. The higher the ash content, the lower the quality of the fuel. The purpose of the ash determination is to calculate the amount of inorganic residue from the combustion of biofuel, expressed as a percentage by mass of dry matter (DM). The experiment was performed three times with each type of pellet. The ash content was determined by completely burning the different types of biofuel pellets and weighing the resulting ash. The tests were carried out in the test rig with an ash measurement error of $0.1 \%$. The weight of each sample was about $2-3 \mathrm{~g}$, and each test was repeated three times [30]. An IKA C 5000 calorimeter with a bomb calorimeter was used for the determination of the heat of combustion, and the calorific value was calculated taking into account the heat of combustion, humidity, and other elements [31]. To make the experiments more accurate, the pellet samples were first dried. During the test, the basic data were entered into the calorimeter computer: the mass of the pellet and the heat released by the burning pellet. At the start of the test, the technical oxygen valve was opened, the required oxygen pressure was set (up to $30 \mathrm{bar}$ ), and the process was controlled by the calorimeter control panel. At the end of the test process, the instrument displayed the net calorific value of the calculated results. The error of the performed measurements was $0.02 \%$.

\subsection{Evaluation of the Influence of Moisture on the Properties of Pellets}

When evaluating the impact of moisture content on the properties of pressed biofuel, it is important to determine the density, destructive compressive force, and lower heating value (LHV) of the pellets of different moisture. It is necessary to evaluate the changes in the range of $5-15 \%$ of moisture content. After studying and evaluating these properties in a complex way, combining them, and describing them theoretically, an empirical model was created and prepared for practical use. Knowing the plant type and moisture (5-15\%) of granulated biofuel with a pellet diameter $D=6.0 \pm 0.5 \mathrm{~mm}$, a length $l=24.2 \pm 1.1 \mathrm{~mm}$, this model will allow determining the density, destructive compressive force, and the lower 
heating value of investigated coarse stem plant granules. All calculations and results for these dependencies are presented in the Results and Discussion chapter.

\subsection{Analysis of Environmental Impact of Burning Biofuel Pellets}

In solid biofuel boilers, fuel combustion and emission concentrations depend on the type, quality, and shape of the fuel and the combustion of the solid fuel boiler. In order to elucidate the influence of these parameters on the formation of pollutants, studies were performed in a low-power solid fuel boiler-pellet fireplace type stove Astra P-5 (Astra, Alytus, Lithuania). The mass of the sample of combusted pellets was about $5 \mathrm{~kg}$. Before starting the test, the boiler was preheated for 8-10 min by burning wood sawdust pellets. The nominal power of the boiler was $5 \mathrm{~kW}$, and the average flue gas temperature was $105-250^{\circ} \mathrm{C}$. The research was carried out at the Lithuanian Energy Institute, and the formed pollutants were measured with the combustion product analyzers Datatest $400 \mathrm{CEM}$ and VE7. The burning of each sample lasted for about $10 \mathrm{~min}$, and the emissions of harmful substances into the environment by burning biofuel pellets $\left(\mathrm{CO}_{2}, \mathrm{CO}, \mathrm{NO}_{\mathrm{x}}\right.$, and $\left.\mathrm{C}_{\mathrm{x}} \mathrm{H}_{\mathrm{y}}\right)$ were recorded.

Emission limit values for combustion plants are regulated by the emission standards approved by the Minister of Environment of the Republic of Lithuania (LAND 43-2013) [32]. These standards regulate pollutant limits for biofuel that is burned, including grass plants and straw. Pollutant emission limit values for new and existing biofuel combustion devices were identified (at a standard $\mathrm{O}_{2}=6 \%$ concentration by volume percentage) (LAND 43-2013) [32]: $\mathrm{NO}_{\mathrm{x}} \rightarrow 750 \mathrm{mg} \mathrm{Nm}^{-3}$; $\mathrm{SO}_{2} \rightarrow 2000 \mathrm{mg} \mathrm{Nm}^{-3}$; $\mathrm{CO} \rightarrow$ not regulated; solid particles $\rightarrow 800 \mathrm{mg} \mathrm{Nm}^{-3}$.

CO emission limit values for manually and automatically loaded solid fuel boilers with a thermal input of up to $500 \mathrm{~kW}$ are given in another standard (LST EN 303-5: 2012) [33]. According to the requirements of this standard, the following permissible CO emission values have been established for boilers with automatic load: 3000 ppm for Class 3, 1000 ppm for Class 4, and 500 ppm for Class 5 boilers.

In experimental studies analyzing and evaluating the most important properties of granular biofuel, the research data were statistically evaluated by performing one-way analysis of variance, correlation, and regression [34]. ANOVA software was used to determine the limits of the significant (substantial) difference between the probability levels of R05 and R01 according to the P criterion [35]. SigmaStat and SYSTAT software were used for correlation analysis.

\section{Results and Discussion}

\subsection{Physical-Mechanical, Chemical, and Thermal Properties of the Pellets}

\subsubsection{Biometrics, Mass, and Density of the Granules}

The density of biofuel pellets indicates the mass per unit volume of the compressed material. The density of compressed biomass depends on the temperature of the material (the material weighs less at higher temperatures) and the moisture content of the material (the higher the moisture content, the higher the density). The recommended pellet density is given in various standards, ranging from 600 to $1200 \mathrm{~kg} \mathrm{~m}^{-3}$ [36-38].

After examining the most important physical-mechanical properties of granular biofuel of coarse stem plants, the obtained results are presented in Table 1 . The density of the investigated granules is given in the dry matter (DM).

Table 1. Biometrics, mass, and density of the granules.

\begin{tabular}{ccccc}
\hline Plant Species & Diameter $\boldsymbol{d}, \mathbf{m m}$ & Length $\boldsymbol{l}, \mathbf{m m}$ & Mass $\boldsymbol{m}, \mathbf{g}$ & Density $\boldsymbol{S}, \mathbf{k g ~ m}^{-\mathbf{3}} \mathbf{D M}$ \\
\hline Miscanthus & $6.36 \pm 0.15$ & $24.84 \pm 1.13$ & $0.57 \pm 0.05$ & $713.5 \pm 67.1$ \\
\hline Sida & $6.07 \pm 0.15$ & $23.72 \pm 0.82$ & $0.74 \pm 0.09$ & $1072.3 \pm 43.4$ \\
\hline Cup plant & $6.35 \pm 0.34$ & $24.07 \pm 1.24$ & $0.72 \pm 0.12$ & $945.5 \pm 48.1$ \\
\hline
\end{tabular}


The highest density of granules of coarse stem herbaceous plants was found to be of sida $\left(1072.3 \pm 43.4 \mathrm{~kg} \mathrm{~m}^{-3} \mathrm{DM}\right)$ and the lowest of Miscanthus $\left(713.5 \pm 67.1 \mathrm{~kg} \mathrm{~m}^{-3} \mathrm{DM}\right)$. According to the results, the pellet density of all tested plants exceeded $700 \mathrm{~kg} \mathrm{~m}^{-3}$, and the recommended pellet density specified in the standards of various countries ranges from 600 to $1200 \mathrm{~kg} \mathrm{~m}^{-3}$ [27]. Therefore, it can be stated that the pellets tested meet the standards.

\subsubsection{Elemental Composition, Ash Content, and the Lower Heating Value of the Granules}

The results of various scientific studies show that biofuel pellets of plant origin consist of three main components: carbon $(\mathrm{C})$, hydrogen $(\mathrm{H})$, and oxygen $(\mathrm{O})$, which together account for the majority of biofuel composition, as much as $81-93 \%$.

The elemental composition, ash content, and lower heating value (LHV) of the studied biofuel pellets of coarse stem plants are presented in Table 2. The analysis of the elemental composition, ash content, and lower heating value of three types of granules of different coarse stem plants showed that the highest content of $\mathrm{C}$ (carbon) differed slightly from $45.44 \%$ to $46.22 \%$, and the content of $\mathrm{O}$ (oxygen) was ranged from $38.57 \%$ to $41.94 \%$, and $\mathrm{H}$ (hydrogen) between 5.28 and 5.61\%. Small amounts of other chemicals such as N (nitrogen), $\mathrm{S}$ (sulfur), and $\mathrm{Cl}$ (chlorine) were found as well.

Table 2. Elemental composition, ash content, and lower heating value of coarse stem plant granules (in dry matter, DM).

\begin{tabular}{lccc}
\hline \multirow{2}{*}{ Parameter } & \multicolumn{3}{c}{ Coarse Stem Plant Species } \\
\cline { 2 - 4 } & Miscanthus & Sida & Cup Plant \\
\hline $\mathrm{C}$ (carbon) content, \% & $46.22 \pm 1.18$ & $45.46 \pm 1.14$ & $45.44 \pm 1.16$ \\
\hline $\mathrm{H}$ (hydrogen) content, \% & $5.37 \pm 0.45$ & $5.61 \pm 0.47$ & $5.28 \pm 0.46$ \\
\hline $\mathrm{N}$ (nitrogen) content, \% & $0.90 \pm 0.32$ & $0.75 \pm 0.31$ & $0.68 \pm 0.32$ \\
\hline $\mathrm{S}$ (sulfur) content, \% & $0.11 \pm 0.07$ & $0.17 \pm 0.07$ & $0.07 \pm 0.01$ \\
\hline $\mathrm{O}$ (oxygen) content, \% & $38.57 \pm 0.0$ & $41.94 \pm 0.0$ & $38.57 \pm 0.0$ \\
\hline $\mathrm{Cl}$ (chlorine) content, \% & $0.56 \pm 0.0$ & - & - \\
\hline Ash content, \% & $8.84 \pm 0.90$ & $6.07 \pm 0.11$ & $9.96 \pm 0.38$ \\
\hline Lower heating value (LHV), $\mathrm{MJ} \mathrm{kg}^{-1} \mathrm{DM}$ & $17.84 \pm 0.80$ & $17.43 \pm 0.74$ & $16.82 \pm 0.89$ \\
\hline
\end{tabular}

The ash content (in dry matter) in the investigated pellets was found to be quite high, as it reached $6.07 \%$ after burning sida pellets, and $9.96 \%$ after burning cup plant pellets. Such a high amount of ash indicates that the pellets of the cup plant did not burn well enough and, compared to other energy crops, their lower heating value was lower: $16.82 \pm 0.89 \mathrm{MJ} \mathrm{kg}^{-1}$ (Table 2).

Based on the results of these studies, it can be stated that the use of cup plants for the production of granular biofuel is not justified enough, as some of their properties do not sufficiently meet the requirements for biofuel. However, these plants can be used in a mixture with wood waste (sawdust) or other energy crops.

Other researchers have also investigated coarse herbaceous plants. Monti et al. studied Miscanthus, giant reed, and switchgrass and evaluated their biomass properties and ash content. The results of their research showed that the ash content of giant reed was higher than that of Miscanthus [39]. The ash content of herbaceous plant leaves was also found to be higher, and both plants had lower ash content in winter than in autumn [40].

Stolarski et al. investigated the genotypes of 26 perennial plants and evaluated their thermophysical properties and elemental composition. These studies showed that, when harvesting semi-woody grasses and grasses at later dates, compared to short-rotation energy plants, biomass had a significantly reduced moisture content and increased the 
lower heating value, while short-rotation woody plants had lower ash content and higher carbon and hydrogen content [41].

Based on the performed research, we can state that the pellets of many coarse stem plants have similar properties to wood. The requirements of the standard for wood biofuels are as follows: total moisture $\leq 10 \%$, ash content $\leq 1.5 \%$ (up to $7 \%$ allowed for herbaceous plant biomass), and lower heating value $\geq 17.0 \mathrm{MJ} \mathrm{kg}^{-1}$. Both the elemental composition and the lower heating value compared to wood standards have close values. Although the ash content of the coarse stem herbaceous plants studied is higher, they can be used for combustion by combining the combustion process of granular biofuel with the removal of larger amounts of ash.

In order to determine the relationship between the most important quality characteristics of the coarse herbaceous plant biofuel pellets investigated, a correlation was established between the biofuel indicators. The correlations $(r)$ of the properties of coarse herbaceous plant pellets are given in Table 3 .

Table 3. Correlations of determined coarse herbaceous plants pellet indicators $(r)$.

\begin{tabular}{|c|c|c|c|c|c|c|}
\hline \multirow[b]{2}{*}{ Influencing Factor, $x$} & \multicolumn{6}{|c|}{ Dependent Factor, Y } \\
\hline & $\begin{array}{l}\text { Density of } \\
\text { the Pellets, } \\
\mathrm{kg} \mathrm{m}^{-3}\end{array}$ & $\begin{array}{l}\mathrm{C}(\text { Carbon) } \\
\text { Content, \% }\end{array}$ & $\begin{array}{c}\text { H (Hydrogen) } \\
\text { Content, \% }\end{array}$ & $\begin{array}{l}\text { O (Oxygen) } \\
\text { Content, \% }\end{array}$ & Ash Content, $\%$ & $\begin{array}{c}\text { Lower Heating } \\
\text { Value of Dry } \\
\text { Fuel, MJ kg-1 }\end{array}$ \\
\hline Density of the pellets, $\mathrm{kg} \mathrm{m}^{-3}$ & 1.000 & -0.929 & 0.575 & 0.770 & -0.561 & -0.547 \\
\hline C (carbon) content, $\%$ & - & 1.000 & $\mathrm{n}$ & -0.480 & $\mathrm{n}$ & 0.817 \\
\hline H (hydrogen) content, \% & - & - & 1.000 & 0.965 & $-1.000 *$ & 0.371 \\
\hline O (oxygen) content, \% & - & - & - & 1.000 & -0.960 & $\mathrm{n}$ \\
\hline Ash content, $\%$ & - & - & - & - & 1.000 & -0.386 \\
\hline
\end{tabular}

Note: $\mathrm{n}$-weak correlation; ${ }^{*}$ - correlation at $95 \%$ level of confidence. The dash shows that the correlation has been provided above.

Correlation analysis of the properties of the pellets produced from different coarse stem herbaceous plants revealed that the pellet density had a partial effect on the content of hydrogen $\mathrm{H}$ and oxygen $\mathrm{O}$. As the pellet density increased, carbon content, ash content, and lower heating value of the fuel decreased (Table 3). There was a moderate and sufficiently strong interdependence between carbon and oxygen $(r=-0.480)$ as well as between carbon and the lower heating value $(\mathrm{r}=0.817)$. A strong relationship of hydrogen with oxygen $(\mathrm{r}=0.965)$ and ash content in granules $(\mathrm{r}=-1.000 *)$ was found. Hydrogen and ash content had a weak correlation with the lower heating value $(r=0.371$ and $r=-0.386$, respectively), and oxygen had a strong negative correlation with ash content $(r=-0.960)$.

\subsection{Dependence of Density, Destructive Compressive Force, and Lower Heating Value of Biofuel} Pellets on Moisture

\subsubsection{Dependence of Density of Biofuel Pellets on Moisture}

Moisture dependence on the density of various plant granules was investigated and determined by the linear regression method [42] (Figure 1). It can be observed from the graphs that the density decreases linearly with increasing moisture.

Linear regression lines are obtained using the linear equation [42]:

$$
\rho=a w+b
$$

where: $\rho$-density of the pellets, $\mathrm{kg} \mathrm{m}^{-3} ; w$-moisture content of the pellets, $\% ; a, b-$ equation coefficients.

In all studies, the moisture ranged from $5 \%$ to $15 \%$. The values of the coefficients of the linear Equation (1) were determined by the linear regression method using the data from experimental studies. 
The moisture dependence of the pellets of coarse stem herbaceous plants determines the ability of the granules to change their mass depending on the amount of water in them. The analysis of the obtained research results shows that the highest density was observed in the pellets of sida $\left(1180 \mathrm{~kg} \mathrm{~m}^{-3}\right)$. The highest decrease $(63 \%)$ in the density of these pellets at variable moisture from $5 \%$ to $15 \%$ was also detected.

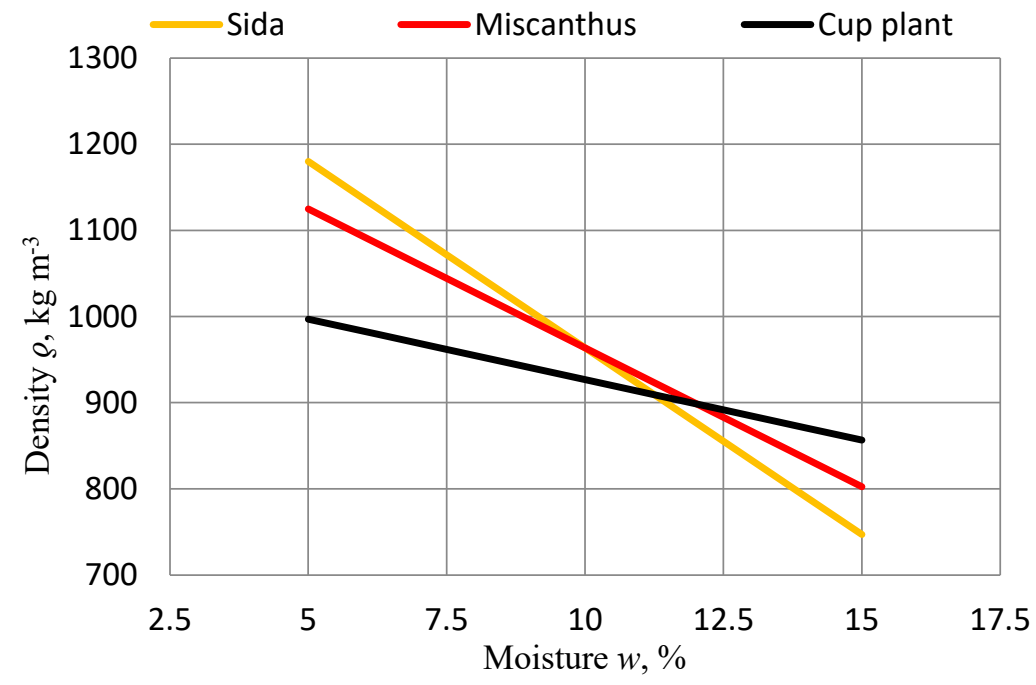

Figure 1. Dependence of density of biofuel pellets on moisture.

The influence of any dependence argument on the function is determined by its derivative; thus, for the pellets of any plant species studied, we have:

$$
\frac{d \rho}{d w}=a_{\rho}, \frac{d F}{d w}=a_{F}, \frac{d Q}{d w}=a_{Q}
$$

where $a_{\rho}, a_{F}, a_{Q}$ are quantities of the influence of moisture on the density of the pellets (sida, Miscanthus, and cup plant), respectively. Therefore

$$
k_{\rho}=\left|a_{\rho}\right|, k_{F}=\left|a_{F}\right|, k_{Q}=\left|a_{Q}\right|,
$$

where $k_{\rho}, k_{F}, k_{Q}$ may be used as a criterion to quantify the effect of moisture on density. $a_{\rho}, a_{F}, a_{Q}$ are the tangents to the angles of the regression lines, and their absolute values are used because $a_{\rho}, a_{F}, a_{Q}$ of all the plants studied may be negative or zero.

Given that $a_{\rho}>0, a_{F}>0, a_{Q}>0$, the minimum and maximum values of sida, Miscanthus and cup plant densities are equal to:

$$
\begin{gathered}
\rho_{\min }=15 a_{\rho}+b_{\rho}, \rho_{\max }=5 a_{\rho}+b_{\rho} \\
F_{\min }=15 a_{F}+b_{F}, F_{\max }=5 a_{F}+b_{F} \\
Q_{\min }=15 a_{Q}+b_{Q}, F_{\max }=5 a_{Q}+b_{Q}
\end{gathered}
$$

These are new studies, and it can be said that the dependence of plant granule density on moisture has not been studied before.

\subsubsection{Dependence of Destructive Compressive Force of Biofuel Pellets on Moisture}

The physical-mechanical properties of coarse stem herbaceous plant pellets, such as resistance to compression (or destructive compressive force), were determined using INSTRON 5965 equipment. Similar to the evaluation of the pellet density dependencies, the moisture dependencies on the destructive compressive force of various coarse stem and fibrous plant granules were investigated and determined.

These studies have shown that the density and the destructive compressive force of the pellets vary widely depending on the type of plant. The graphs show that the 
determined destructive compressive force decreases linearly with increasing moisture. Moisture limits ranged from $5 \%$ to $15 \%$. The values of the coefficients of the linear equations were determined using experimental research data.

Linear regression lines were obtained using the linear regression equation [33]:

$$
F=a w+b
$$

where $F$-the destructive compressive force of the pellets, $N$; $w$-pellet moisture content, $\%$; $a, b$-equation coefficients.

Dependence of the destructive compressive force of biofuel pellets on moisture is shown in Figure 2.

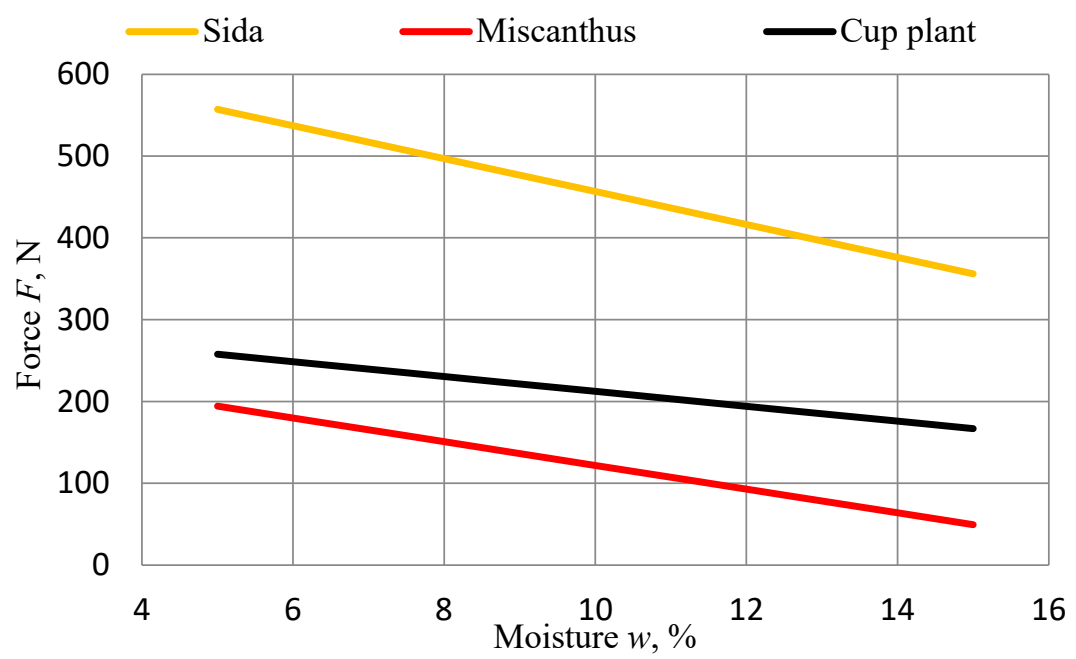

Figure 2. Dependence of destructive compressive force (compressive strength) of biofuel pellets on moisture.

The destructive compressive force of biofuel pellets indicates the strength of the pellet, depending on the amount of water in it. Using a linear equation, the nature of the change of the destructive compressive force of the pellets as a function of moisture was calculated. Sida pellets were found to be the strongest and most resistant to compression, with the destructive compressive force even several times higher than that of other coarse stem herbaceous plants The destructive compressive force of sida pellets varied from 557 to $356 \mathrm{~N}$ (with a moisture increase from 5\% to 15\%). The pattern of variation of all plant pellets was similar, indicating that moisture had a similar effect on the strength of all plant pellets.

\subsubsection{Dependence of Lower Heating Value of Biofuel Pellets on Moisture}

Heating value is the amount of heat released when one kilogram of fuel is completely burned [17]. In this section, the results of experimental and analytical heating value studies of pellets are presented, and the dependencies of the lower heating value (LHV) of coarse stem and fibrous plant pellets on moisture are calculated and plotted (Figure 3). The graphs show that the lower heating value decreases linearly with increasing moisture.

As in previous studies of moisture dependence on pellet density and compressive force, moisture ranged from $5 \%$ to $15 \%$. The values of the coefficients of the linear regression equations were determined using experimental research data and calculation results.

Linear regression lines were obtained using the following linear regression equation [42]:

$$
Q=a w+b
$$

where $Q$-the lower heating value of the pellets, $\mathrm{MJ} \mathrm{kg} \mathrm{kg}^{-1} ; w$-the moisture content of the pellets, $\% ; a, b$-equation coefficients. 


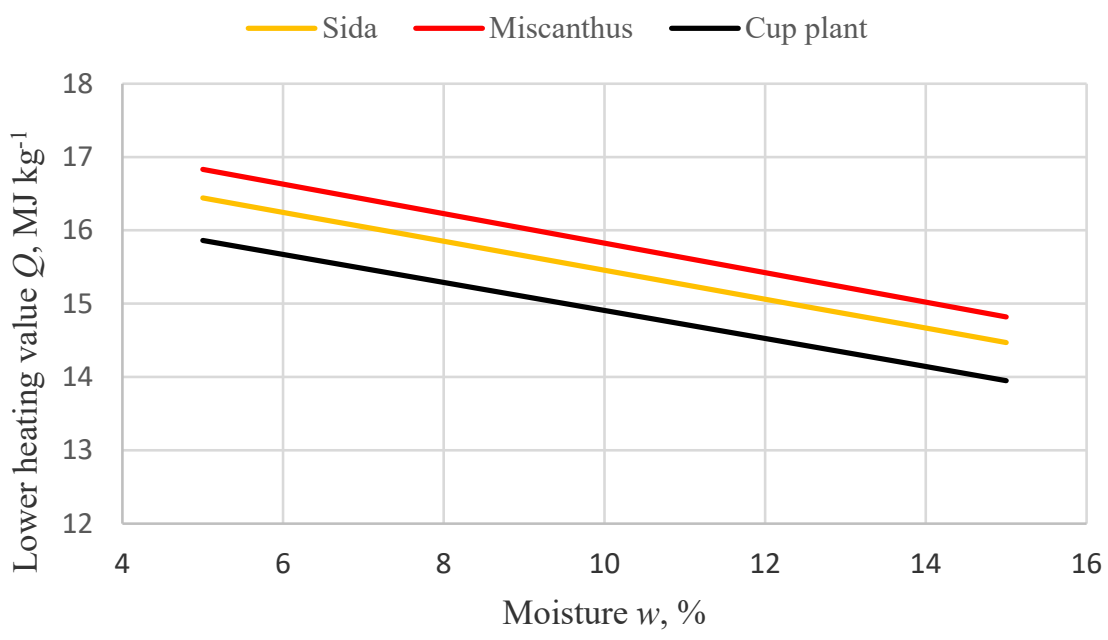

Figure 3. Dependence of lower heating value of biofuel pellets on moisture.

The lower heating value (LHV) of biofuel pellets of coarse stem plants and other plants is widely used to describe the thermal properties of the fuel and its calorific value. Using the linear equation, the dynamics of the change in the lower heating value of the pellets as a function of moisture was calculated. Of the coarse stem plants, Miscanthus pellets were found to be the most calorific, the lower heating value of which decreased from 16.8 to $14.8 \mathrm{MJ} \mathrm{kg}^{-1}$ with the increase in pellet moisture from $5 \%$ to $15 \%$. The nature of the dependence of the lower heating value of the pellets on the change in moisture content was similar, as the conversion from dry to wet calorific fuel was performed using the same equation [17]. This shows that moisture had the same effect on the heating value of all plant pellets, as the determined lower heating value of biofuel pellets decreased with increasing moisture.

The analysis of criterion $k$, calculated on the influence of the moisture of the studied plants on the properties of the granules, gave the following results:

- Among the studied coarse-stemmed plants, the highest influence of moisture on density was observed in sida $(k=34.280)$, and the lowest in cup plant $(k=14.048)$.

- The highest influence of moisture on the destructive compressive force was in Miscanthus $(k=14.5)$ and the lowest in cup plant $(k=9.1)$.

- The highest influence of moisture on the lower heating value was in Miscanthus $(k=0.198)$, and the lowest in sida $(k=0.195)$.

\subsection{Linear Regression Model of the Effect of Pellet Moisture on Their Density, Strength, and} Thermal Properties

In order to evaluate the results of experimental studies on the influence of moisture on the properties of pelleted biofuel, the following properties of $5-15 \%$ moisture granules of 15 species of plants were presented and discussed: density, destructive compressive force, lower heating value, and their dynamics. A program has been developed to evaluate these properties.

This program can be applied to any number of types of granular biofuel from herbaceous plants studied $m_{1}$, with the pellet diameter $D=6.0 \pm 0.5 \mathrm{~mm}$ and the length $L=20.0 \pm 5.0 \mathrm{~mm}$, to evaluate the characteristics. By specifying the type and moisture (in the range of $5-15 \%$ ) of the plant, this program can be used to determine the dynamics of the change in pellet density, the destructive compressive force, and the lower heating value as the pellet moisture changes, and to visualize the impact criteria and the results obtained.

The initial data are presented in matrix $d$. The data are compiled of $m_{1}=15$ different species of plant pellet density, destructive compressive force, and lower heating value $[m \times n]$ in matrix $d$ : 


$\left(\begin{array}{cccccccccc}\text { Pellet } & a_{\rho} & b_{\rho} & R_{\rho}^{2} & a_{F} & b_{F} & R_{F}^{2} & a_{Q} & b_{Q} & R_{Q}^{2} \\ \text { Sida } & -43.295 & 1397.000 & 0.999 & -20.107 & 657.730 & 0.977 & -0197 & 17.430 & 0.996 \\ \text { Miscanthus } & -32.229 & 1286.000 & 0.924 & -14.495 & 266.870 & 0.695 & -0.201 & 17.840 & 0.995 \\ & & & & & & & & & \\ \text { Cup plant } & -14.048 & 1067.000 & 0.858 & -9.079 & 303.180 & 0.988 & -0.191 & 16.820 & 0.991\end{array}\right)$

The elements of the matrix $d_{i j}$ are numbered from $i=0, j=0$; therefore, the number of rows of the matrix is $m=m_{1}+1$; if the number of pellet types tested is $m_{1}$, the number of columns is $n=n_{1}+1$; if the number of regression coefficients is $n_{1}$, the number of characteristics to be analyzed is $n_{2}$. For the tested case: $m_{1}=15, n_{1}=15$, and $n_{2}=3$; therefore, $m=16$ and $n=10$.

The notations used in the matrix $d$. For the coefficients of the regression equation: $a_{\rho}, b_{\rho}$-for the density, $a_{F}, b_{F}$-for the destructive compressive force, and $a_{Q}, b_{Q}$-for the lower heating value; correlation coefficients: $R_{\rho}$-for the density, $R_{F}$-for the destructive compressive force, and $R_{Q}$-for the lower heating value.

We then have a regression equation for the density and corresponding correlation coefficients for any type of pellet tested:

$$
\rho(i, w)=d_{i 1} w+d_{i 2}, R_{\rho}(i)=-\sqrt{d_{i 3}}, i=1,2, \ldots, 9,
$$

for the destructive compressive force and corresponding correlation coefficients

$$
F(i, w)=d_{i 4} w+d_{i 5}, R_{F}(i)=-\sqrt{d_{i 6}}, i=1,2, \ldots, 9,
$$

for the lower heating value and corresponding correlation coefficients

$$
Q(i, w)=d_{i 7} w+d_{i 8}, R_{Q}(i)=-\sqrt{d_{i 9}}, i=1,2, \ldots, 9,
$$

where $w$-moisture content, and $i$-the type of pellet.

Maximum and minimum moisture impact criteria (2), when $5 \leq w \leq 15$ : for the density:

$$
k_{\rho \max }=\max _{1 \leq i \leq 15}\left|d_{i 1}\right|, k_{\rho \min }=\min _{1 \leq i \leq 15}\left|d_{i 1}\right|
$$

for the destructive compressive force:

$$
k_{F \max }=\max _{1 \leq i \leq 15}\left|d_{i 4}\right|, k_{F \min }=\min _{1 \leq i \leq 15}\left|d_{i 4}\right|
$$

for the lower heating value:

$$
k_{Q \max }=\max _{1 \leq i \leq 15}\left|d_{i 7}\right|, k_{Q \min }=\min _{1 \leq i \leq 15}\left|d_{i 7}\right|
$$

Maximum and minimum, when $5 \leq w \leq 15$, applying (3): density values

$$
\rho_{\max }=\max _{1 \leq i \leq 15}\left(5 d_{i 1}+d_{i 2}\right), \rho_{\min }=\min _{1 \leq i \leq 15}\left(5 d_{i 1}+d_{i 2}\right)
$$

destructive compressive force values

$$
F_{\max }=\max _{1 \leq i \leq 15}\left(5 d_{i 4}+d_{i 5}\right), F_{\min }=\min _{1 \leq i \leq 15}\left(5 d_{i 4}+d_{i 5}\right)
$$

lower heating values

$$
Q_{\max }=\max _{1 \leq i \leq 15}\left(5 d_{i 7}+d_{i 8}\right), Q_{\min }=\min _{1 \leq i \leq 15}\left(5 d_{i 7}+d_{i 8}\right)
$$


All lines were calculated and plotted using the matrix method, but they are not presented in the paper because their overall picture and linear nature of change correspond to the picture of the graphs above.

\subsection{Harmful Emissions Determined When Burning Biofuel Pellets}

Emissions of plant pellets from combustion determine the quality and suitability of the fuel. Compared to the requirements of LAND 43-2013 and LST EN 303-5: 2012 [32,33], the emissions of pellets of the coarse stem herbaceous plants studied did not exceed the maximum permissible concentration (only the emissions of cup plant have not been determined). Table 4 shows the emissions from the combustion of pressed coarse stem plants.

Table 4. Emissions from burning coarse stem plant pellets.

\begin{tabular}{lcccc}
\hline \multirow{2}{*}{ Plant Species } & $\mathbf{C O}_{\mathbf{2}}$ & $\mathbf{C O}$ & $\mathbf{N O}_{\mathbf{x}}$ & $\mathbf{C}_{\mathbf{x}} \mathbf{H}_{\mathbf{y}}$ \\
\cline { 2 - 6 } & $\mathbf{\%}$ & $\mathbf{p p m}$ & $\mathbf{p p m}$ & $\mathbf{p p m}$ \\
\hline Miscanthus & 5.2 & 2294.7 & 216.1 & 61 \\
\hline Sida & 7.9 & 1252.5 & 215.1 & 24 \\
\hline
\end{tabular}

When burning the pellets from cup plants, it was not possible to detect the emission of harmful substances because the pellets burned poorly and emitted a large amount of smoke, resulting in the release of a lot of harmful gases into the environment. In order to completely burn these pellets in the solid fuel boiler used, the operating modes and parameters of the combustion equipment should be further changed in search of the optimal combustion process for biofuel pellets.

The lowest concentrations of $\mathrm{CO}, \mathrm{NO}_{x}$, and $\mathrm{C}_{\mathrm{x}} \mathrm{H}_{\mathrm{y}}$ harmful gases were obtained by burning sida pellets (1252.5, 215.1, and 24 ppm, respectively), and higher emissions were obtained by burning Miscanthus pellets. Lower $\mathrm{CO}_{2}$ content was obtained by burning Miscanthus pellets (5.2\%). Sulfur dioxide $\mathrm{SO}_{2}$ emissions were not recorded during the combustion of pellets of various species of coarse herbaceous plants.

For comparison, Polish researchers found hydrocarbon $\left(\mathrm{C}_{\mathrm{x}} \mathrm{H}_{\mathrm{y}}\right)$ emissions from burning wood pellets at concentrations ranging from 24 to $61 \mathrm{ppm}$. Researchers in the US and Poland have determined $\mathrm{NO}_{x}$ emissions from burning wood biomass to be $170 \mathrm{mg} \mathrm{m}^{-3}$ [43] Other researchers have studied the concentrations of $\mathrm{CO}$ in the combustion of straw pellets $\left(6.4 \pm 5.0 \mathrm{~g} \mathrm{~kg}^{-1}\right)$ and wood pellets $\left(1.3 \pm 1.9 \mathrm{~g} \mathrm{~kg}^{-1}\right)$ [44]. Sipula and other researchers burned peat and determined $\mathrm{CO}$ and $\mathrm{NO}_{\mathrm{x}}$ emissions at $140 \pm 297$ and $225 \pm 229 \mathrm{mg} \mathrm{MJ}^{-1}$, respectively [45]. Finnish researchers studied wood and reed canary grass and determined that the emissions from their combustion had $\mathrm{CO}$ concentrations of $9.6 \pm 3.1 \mathrm{mg} \mathrm{MJ}^{-1}$ and $\mathrm{NO}_{\mathrm{x}}$ concentrations of $212 \pm 217 \mathrm{mg} \mathrm{MJ}^{-1}$ [46]. Sosa and other researchers have also studied emissions from burning knotweed pellets and found $\mathrm{CO}$ concentrations of $928.9 \mathrm{mg} \mathrm{m}^{-3}$ and $\mathrm{NO}_{x}$ concentrations of $297.0 \mathrm{mg} \mathrm{m}^{-3}$ [47]. Czech researchers have studied the concentrations of $\mathrm{CO}$ and $\mathrm{NO}_{x}$ emissions from reed canary grass, giant knotweed, and Miscanthus pellets during combustion. The concentrations of $\mathrm{CO}$ and $\mathrm{NO}_{\mathrm{x}}$ emissions when burning Miscanthus were found to be 543 and $167 \mathrm{mg} \mathrm{m}^{-3}$, respectively [48].

In the analysis of atmospheric carbon dioxide concentration, it was observed that it is constantly rising. For example, in pre-industrial times, the concentration of carbon dioxide was $270 \mathrm{ppm}$, and in recent years it has increased significantly to $400 \mathrm{ppm}$. Analyzing the prospects for ambient air pollution, $\mathrm{CO}_{2}$ concentrations are estimated to increase to 450 ppm by 2030 due to fossil fuel combustion and projected changes in fuel use [49,50]. However, the EU-28 paper states that $\mathrm{CO}_{2}$ emissions have been reduced significantly over the last two decades [50].

Summarizing study's results on pellet combustion and emissions, it can be stated that coarse stem plants grown in Lithuania can be recommended to be used as biofuel for pressing, but if the plant biomass has a high moisture content, then additional energy is 
needed to dry this biomass. Burning such biofuel is a high-quality and efficient process with low harmful emissions to the environment.

\section{Conclusions}

The physical, mechanical, and chemical properties of coarse stem herbaceous plant pellets-density, moisture content, compressive force, ash content, heating value, elemental composition, and measured granule emissions-were comprehensively investigated and determined. After determining the density of granules, sida granules had the highest value of $1072.3 \pm 43.4 \mathrm{~kg} \mathrm{~m}^{-3}$ and Miscanthus granules the lowest value $\left(713 \mathrm{~kg} \mathrm{~m}^{-3}\right)$. The results of research on the elemental composition of various plants showed that the highest $\mathrm{C}$ (carbon) content was $45.5-48.0 \%, \mathrm{O}$ (oxygen) content was $41.0-42.9 \%$, and $\mathrm{H}$ (hydrogen) content was 5.7-5.9\%. Investigated plants also contained small amounts of $\mathrm{N}$ (nitrogen) and $\mathrm{S}$ (sulfur). The dependencies of moisture content on pellet density, destructive compressive force, and lower heating value (LHV) were determined. Dependencies changed linearly in the selected range of pellet moisture of $5-15 \%$. The criterion $k$ was used to quantify the effect of moisture on the pellet qualitative indicators, and the following results were obtained: the highest influence of moisture on density was observed in sida $(k=34.280)$, and the lowest in cup plant $(k=14.048)$; the highest influence on destructive compressive force was in Miscanthus $(k=14.5)$, and the lowest in cup plant $(k=9.1)$; the highest influence on the lower heating value was in Miscanthus $(k=0.198)$, and the lowest in sida $(k=0.195)$. Investigations of harmful gas emissions $\left(\mathrm{CO}_{2}, \mathrm{CO}, \mathrm{NO}_{\mathrm{x}}\right.$ and $\left.\mathrm{C}_{\mathrm{x}} \mathrm{H}_{\mathrm{y}}\right)$ from the combustion of sida and Miscanthus pellets have shown that lower concentrations of $\mathrm{CO}, \mathrm{NO}_{\mathrm{x}}$, and $\mathrm{C}_{\mathrm{x}} \mathrm{H}_{\mathrm{y}}$ harmful gases were obtained from the combustion of sida pellets $(1252.5,215.1$, and $24 \mathrm{ppm}$, respectively), and lower $\mathrm{CO}_{2}$ content was detected from burning Miscanthus pellets (5.2\%). These results revealed that the detected concentrations of harmful gases did not exceed the permissible levels.

The results of the presented research have shown that when preparing biofuel pellets from coarse stem herbaceous plants, ecological biofuel is obtained. The most important properties (physical, mechanical, chemical, energy, and thermal) of this fuel meet the requirements for high-quality solid biofuel. Based on the results of this research, it can be stated that the most suitable plant for the preparation of granulated biofuel is sida, and the use of a cup plant for solid biofuel requires further research, as some of its properties do not meet the requirements for biofuel quality.

Author Contributions: Conceptualization, A.J., V.K. and D.S.; methodology, A.J., V.K., D.S., R.D. and G.G.; validation, A.J.; formal analysis, A.J., V.K., D.S. and M.T.V.; investigation, A.J., D.S., E.V. and G.G.; data curation, A.J., V.K., D.S. and G.G.; writing-original draft preparation, A.J., V.K. and D.S.; writing-review and editing, A.J., V.K., D.S., R.D., E.V., G.G. and M.T.V.; supervision, A.J. and D.S.; funding acquisition, A.J. and R.D. All authors have read and agreed to the published version of the manuscript.

Funding: This research received no external funding.

Institutional Review Board Statement: Not applicable.

Informed Consent Statement: Not applicable.

Data Availability Statement: Not applicable.

Conflicts of Interest: The authors declare that there is no conflict of interest.

\section{References}

1. Šiaudinis, G.; Jasinskas, A.; Šarauskis, E.; Steponavičius, D.; Karčiauskienè, D.; Liaudanskienè, I. The assessment of Virginia mallow (Sida hermaphrodita Rusby) and cup plant (Silphium perfoliatum L.) productivity, physico-mechanical properties and energy expenses. Energy 2015, 93, 606. [CrossRef]

2. Stolarski, M.J.; Krzyzaniak, M.; Warminski, K.; Tworkowski, J.; Szczukowski, S. Willow biomass energy generation efficiency and greenhouse gas reduction potential. Pol. J. Environ. Stud. 2015, 24, 2627. [CrossRef] 
3. Ibitoye, S.E.; Jen, T.-C.; Mahamood, R.M.; Akinlabi, E.T. Densification of agro-residues for sustainable energy generation: An overview. Bioresour. Bioprocess 2021, 8, 75. [CrossRef]

4. Wang, Y.; Wang, J.; Zhang, X.; Grushecky, S. Environmental and Economic Assessments and Uncertainties of Multiple Lignocellulosic Biomass Utilization for Bioenergy Products: Case Studies. Energies 2020, 13, 6277. [CrossRef]

5. Raslavičius, L.; Kučinskas, V.; Jasinskas, A. The prospects of energy forestry and agro-residues in the Lithuania's domestic energy supply. Renew. Sustain. Energy Rev. 2013, 22, 419-431. [CrossRef]

6. Cui, X.; Yang, J.; Wang, Z.; Shi, X. Better use of bioenergy: A critical review of co-pelletizing for biofuel manufacturing Carbon Capture Sci. Technol. 2021, 1, 100005. [CrossRef]

7. Černiauskienè, Ž.; Raila, A.J.; Zvicevičius, E.; Kadžiulienè, Ž.; Tilvikienè, V. Analysis of Artemisia dubia Wall growth, preparation for biofuel and thermal conversion properties. Renew. Energy 2018, 118, 468. [CrossRef]

8. Jasinskas, A.; Streikus, D.; Vonzodas, T. Fibrous hemp (Felina 32, USO 31, Finola) and fibrous nettle processing and usage of pressed biofuel for energy purposes. Renew. Energy 2020, 149, 11-21. [CrossRef]

9. Clifton-Brown, J.; Lewandowski, I.; Andersson, B. Performance of 15 Miscanthus Genotypes at Five in Europe. Agron. J. 2001, 93, 1014-1019. [CrossRef]

10. Lewandowski, I.; Jonathan, M.O.; Scurlock, J.M.O.; Lindvall, E.; Christoud, M. The development and current status of perennial rhizomatous grasses as energy crops in the US and Europe. Biomass Bioenergy 2003, 25, 335. [CrossRef]

11. Iglinski, B.; Iglin, A.; Kujawski, W.; Buczkowski, M.; Cichosz, R. Bioenergy in Poland. Renew. Sustain. Energy Rev. 2011, 15, 2999. [CrossRef]

12. Heneman, P.; Cervinka, J. Energy crops and bioenergetics in the Czech Republic. Agric. (Agric. Eng.) 2007, 51, 73-78.

13. Nakanishi, E.Y.; Frias, M.; Santos, S.F.; Rodrigues, M.S.; Vigil de la Villa, R.; Rodriguez, O.; Junior, H.S. Investigating the possible usage of elephant grass ash to manufacture the eco-friendly binary cements. J. Clean. Prod. 2016, 116, 236-243. [CrossRef]

14. Borges Gomes, F.J.; Colodette, J.L.; Burnet, A.; Ribas Batalha, L.A.; Barbosa, B.M. Potential of elephant grass for pulp production. BioResources 2013, 8, 4359-4379. [CrossRef]

15. Lessa, M.O.; Calixto, G.Q.; Chagas, B.M.E.; Aguiar, E.M.; Melo, M.A.F.; Braga, R.M. Energetic characterization and flash pyrolysis of different elephant grass cultivars (Pennisetum purpureum Schum.). Can. J. Chem. Eng. 2021, 24309. [CrossRef]

16. Bilandžija, N.; Krička, T.; Matin, A.; Leto, J.; Grubor, M. Effect of harvest season on the fuel properties of Sida hermaphrodita (L.) Rusby biomass as solid biofuel. Energies 2018, 11, 3398. [CrossRef]

17. Vares, V.; Kask, U.; Muiste, P.; Pihu, T.; Soosaar, S. Manual for Biofuel Users; Tallinn University of Technology: Tallinn, Estonia, 2005; 178p.

18. Nahm, M.; Morhart, C. Virginia mallow (Sida hermaphrodita (L.) Rusby) as perennial multipurpose crop: Biomass yields, energetic valorization, utilization potentials, and management perspectives. GCB-Bioenergy 2018, 10, 393-404. [CrossRef]

19. Lewtak, K.; Fiolka, M.J.; Czaplewska, P.; Macur, K.; Kaczynski, Z.; Buchwald, T.; Szczuka, E.; Rzymowska, J. Sida hermaphrodita seeds as the source of anti-Candida albicans activity. Sci. Rep. 2019, 9, 12233. [CrossRef] [PubMed]

20. Karpinskaite, I. Ornamental Cultivation and Development of Plants for Energy Purposes; Research Work: Siauliai, Lithuania, 2010; p. 11.

21. Koniuszy, A.; Hawrot-Paw, M.; Podsiadlo, C.; Sedlak, P.; Mozdzer, E. Gasification of Cup Plant (Silphium perfoliatum L.) Biomass-Energy Recovery and Environmental Impacts. Energies 2020, 13, 4960. [CrossRef]

22. Sumalan, R.L.; Muntean, C.; Kostov, A.; Krzanovic, D. The cup plant (Silphium perfoliatum L.)—A viable solution for bioremediating soils polluted with heavy metals. Not. Bot. Horti Agrobot. Cluj-Napoca 2020, 48, 2095-2113. [CrossRef]

23. Šiaudinis, G.; Skuodienè, R.; Repšienè, R. The investigation of three potential energy crops: Common mugwort, cup plant and Virginia mallow on Western Lithuania's Albeluvisol. Appl. Ecol. Environ. Res. 2017, 15, 24. [CrossRef]

24. Sulaiman, S.A.; Bamufleh, H.S.; Tamili, S.N.A.; Inayat, M.; Naz, M.Y. Characterization of date palm fronds as a fuel for energy production. Bull. Chem. Soc. Ethiop. 2016, 30, 465-472. [CrossRef]

25. Ren, T.; Enchen, J.; Yan, S.; Xiwei, X.; Shu, R. The pelletization and combustion properties of terrified camelia shell via dry and hydrothermal torrefaction: A comparative evaluation. Bioresour. Technol. 2018, 264, 78-89.

26. Alvarez-Alvarez, P.; Pizarro, C.; Barrio-Anta, M.; Camara-Obregon, A.; Bueno, J.M.L.; Alvarez, A.; Gutierrez, I.; Burslem, D.F. Evaluation of tree species for biomass energy production in northwest Spain. Forests 2018, 9, 160. [CrossRef]

27. Jasinskas, A. Technological-Technical Substantiation and Energetic-Environmental Evaluation of Technological Preparation and Use of Fibrous Plants for Biofuel. MTTV Project of Agriculture, Food Industry and Fisheries; Academy: Kaunas District, Lithuania, 2016; p. 70. (In Lithuanian)

28. EN ISO 18134-1:2015; Solid Biofuels—Determination of Moisture Content—Oven Dry Method—Part 1: Total Moisture-Reference Method. European Committee for Standardization: Brussels, Belgium, 2015.

29. LST EN ISO 16948: 2015; Solid biofuels—Determination of Total Content of Carbon, Hydrogen and Nitrogen (ISO 16948:2015). European Committee for Standardization: Brussels, Belgium, 2015.

30. LST EN ISO 18122: 2016; Solid Biofuels-Determination of Ash Content t (ISO 18122:2015). European Committee for Standardization: Brussels, Belgium, 2016.

31. LST EN ISO 18125: 2017; Solid Biofuels—Determination of Calorific Value (ISO 18125:2017). European Committee for Standardization: Brussels, Belgium, 2017. 
32. LAND 43-2013; Emission Rates for Combustion Plants. Lithuanian Committee for Standardization: Vilnius, Lithuania, 2013. (In Lithuanian)

33. LST EN 303-5: 2012; Heating Boilers. Part 5. Manual and Automatic Loading of Solid Fuel Heating Boilers with a Rated Thermal Input of up to $500 \mathrm{~kW}$. Terminology, Requirements, Testing and Marking. Lithuanian Committee for Standardization: Vilnius, Lithuania, 2012. (In Lithuanian)

34. Raudonius, S.; Jodaugienè, D.; Pupalienė, R.; Trečiokas, K. Research Methodology; Academy: Kaunas, Lithuania, 2009; 34p. (In Lithuanian)

35. Tarakanovas, P.; Raudonius, S. Statistical Analysis of Agronomic Research Data Using Computer Programs Anova, Stat, Split-Plot from the Package SELECTION and IRRISTAT; Academy: Kaunas, Lithuania, 2003; 58p. (In Lithuanian)

36. DIN 51731: 1996-10; Testing of Solid Fuels-Compressed Untreated Wood-Requirements and Testing. European Committee for Standardization: Brussels, Belgium, 2011.

37. Lisowski, A.; Dąbrowska-Salwin, M.; Ostrowska-Ligęza, E.; Nawrocka, A.; Stasiak, M.; Świętochowski, A.; Lisowska, B. Effects of the biomass moisture content and pelleting temperature on the pressure-induced agglomeration process. Biomass Bioenergy 2017, 107, 376-383. [CrossRef]

38. Zeng, T.; Kallio, M.; Ovarainen, H. Critical Review on the Pelletizing Technology, Combustion Technology and Industrial-Scale Systems. IEE/09/758/SI2.558286-MixBioPells. 2012. 133p. Available online: https://www.dbfz.de/fileadmin/MixBioPells/ publications/D31_Critical_Review_about_pelletising_and_combustion_technology_FINAL.pdf (accessed on 11 December 2021).

39. Monti, A.; Zanetti, F.; Scordia, D.; Testa, G.; Cosentino, S.L. What to harvest when? Autumn, winter, annual and biennial harvesting of giant reed, miscanthus and switchgrass in northern and southern Mediterranean area. Ind. Crops Prod. 2015, 75, 129-134.

40. Monti, A.; Di Virgilio, N.; Venturi, G. Mineral composition and ash content ofsix major energy crops. Biomass Bioenergy 2008, 32, 216-223. [CrossRef]

41. Stolarski, M.J.; Śnieg, M.; Krzyżaniak, M.; Tworkowski, J.; Szczukowski, S.; Graban, L.; Lajszner, W. Short rotation coppices, grasses and other herbaceous crops: Biomass properties versus 26 genotypes and harvest time. Ind. Crops Prod. 2018, 119, 22-32. [CrossRef]

42. Bagdonavicius, V.; Kruopis, J.J. Mathematical Statistics 1; Vilnius University: Vilnius, Lithuania, 2015; 293p.

43. Higgins, B.; Yan, L.; Gadalla, H.; Meier, J.; Fareid, T.; Liu, G.; Milewicz, M.; Repczynski, A.; Ryding, M.; Blasiak, W. Biomass co-firing retrofit with ROFA for NOx reduction. Pol. J. Environ. Stud. 2010, 19, 1185.

44. Venturi, P.; Venturi, G. Analysis of energy comparison for crops in European agricultural systems. Biomass Bioenergy 2003, $25,235$. [CrossRef]

45. Sippula, O.; Lamberg, H.; Leskinen, J.; Tissari, J.; Jokiniemi, J. Emissions and ash behavior in a $500 \mathrm{~kW}$ pellet boiler operated with various blends of woody biomass and peat. Fuel 2017, 202, 144. [CrossRef]

46. Prade, T.; Svensson, S.E.; Andersson, A.; Mattsson, J.E. Biomass and energy yield of industrial hemp grown for biogas and solid fuel. Biomass Bioenergy 2011, 35, 3040-3049. [CrossRef]

47. Sosa, L.L.; Jozami, E.; Oakley, L.J.; Montero, G.A.; Ferreras, L.A.; Venturi, G.; Feldman, S.R. Using C4 perennial rangeland grasses for bioenergy. Biomass Bioenergy 2019, 128, 105299. [CrossRef]

48. Szyslak-Barglowicz, J.; Zajac, G.; Slowik, T. Hydrocarbon emissions during biomass combustion. Pol. J. Environ. Stud. 2015, 24, 1349. [CrossRef]

49. IPCC. Climate Change 2014. Mitigation of Climate Change: Working Group III Contribution to the Fifth Assessment Report of the Intergovermental Panel on Climate Change; Cambridge University Press: New York, NY, USA, 2014.

50. Muntean, M.; Guizzardi, D.; Schaaf, E.; Crippa, M.; Solazzo, E.; Olivier, J.G.J.; Vignati, E. Fossil CO $\mathrm{CO}_{2}$ Emissions of all World Countries-2018 Report, EUR 29433 EN; Publications Office of the European Union: Luxembourg, 2018; ISBN 978-92-79-97240-9. [CrossRef] 